\title{
NOTAS SOBRE A TÉCNICA NO PENSAMENTO DE HEIDEGGER
}

\author{
Oswaldo Giacoia Junior*
}

SÍNTESE - O objetivo desse artigo consiste em explicitar e discutir as principais teses do livro de Silvio Vietta a respeito da metafisica e da política na filosofia de Martin Heidegger. De acordo com a interpretação de Vietta, Heidegger empreende uma crítica radical do nacional-socialismo e da política moderna no contexto próprio de sua critica fundamental da metafisica ocidental e de sua reflexão sobre a essência da técnica moderna.

PALAVRAS-CHAVE - metafisica, política, técniCa, ciência, nililismo, valores.

\begin{abstract}
The aim of this article is to explain and to discuss the principal thesis of Silvio Vietta's book concerning to metaphysics and politics in the philosophy of Martin Heidegger. According to Vietta's interpretation, Heidegger undertakes a radical critique on nationalsocialism and on the modem politics in the appropriate philosophycal contex of his fundamental critique on western metaphysics and of his reflexion about the essence (wesen) of modem technincs.

KEY WORDS - metaphysics, politics, technics, science, niilism, values.
\end{abstract}

O presente trabalho se insere entre as interpretações que consideram possivel e indispensável efetuar a passagem da reflexão heideggeriana a respeito da história da metafísica para o âmbito da filosofia prática, privilegiando, no interior desse âmbito, o aspecto ético-político. Para poder fazê-lo, no entanto, torna-se indispensável tomar em consideração a questão da técnica; e, na medida em que se vincula ao aspecto ético também o domínio político da filosofia prática, então a transição pretendida tem que tomar como ponto de partida a reflexão heideggeriana sobre o problema da essência da moderna ciência experimental, posto que é a partir desse horizonte teórico que se pode adequadamente compreender o que há de fundamental na imbricação entre a escalada planetária da moderna tecnologia científica e a crítica da modernidade política.

Foi a preocupação com essa mesma constelação de temas e problemas que norteou minhas duas intervenções anteriores no Colóquio Heidegger de São Paulo: em 1995 procurei trazer elementos que subsidiassem uma reflexão a respeito da posição de Heidegger com relação ao nacional-socialismo, tendo em vista suas posições teóricas a respeito da essência da técnica moderna. Em 1996, a partir da interpretação heideggeriana dos conceitos de vontade de poder e de eterno retor-

* Professor da Universidade Estadual de Campinas, UNICAMP.

\begin{tabular}{|l|l|l|l|l|l|}
\hline VERITAS & Porto Alegre & v. 43 & $\mathrm{n}^{2} 1$ & Março 1998 & p. 97-108 \\
\hline
\end{tabular}


no do mesmo - como noções indispensáveis para promover a compreensão profunda da essência da técnica, procurei elaborar o confronto hermenêutico entre as leituras da obra de Nietzsche empreendidas por Heidegger e por Wolfgang MüllerLauter. No presente Colóquio retorno ao tema da crítica heideggeriana da técnica moderna, fazendo-o por intermédio da relação profunda que se pode identificar entre a filosofia da técnica e a crítica da modernidade política em M. Heidegger. Pretendo, portanto, retomar e discutir as posições concernentes ao pensamento de Heidegger defendidas, por exemplo, por Vitor Farias e Jürgen Habermas - posições filosóficas que são, em considerável medida, inconciliáveis, embora unânimes em sustentar que Heidegger jamais teria se distanciado criticamente de sua adesão oficial, em 1933, quando de sua nomeação para Reitor da Universidade de Freiburg, ao programa sócio-político do nacional-socialismo, programa que procurou interpretar a partir de sua significação metafísica.

Ao retornar ao tema do circuito técnico-político no âmbito de um passo possível, a partir de Heidegger, para a filosofia prática, o presente trabalho se insere também sob o signo conjuntural de uma coincidência feliz: a realização simultânea do terceiro Colóquio Heidegger e o anúncio da disposição, por parte da Editora da Unicamp, de traduzir e publicar o livro de Sílvio Vietta: Heideggers Kritik am Nationalsozialismus und an der Technik. ${ }^{1} \mathrm{O}$ livro de Vietta representa inegavelmente uma das significativas contribuições recentes para a análise de tais questões, não tanto pelo volume de fatos e documentos mobilizados que, em grande parte, já se encontravam exaustivamente recolhidos em trabalhos anteriores ao próprio livro de Vitor Farias, mas, sobretudo, pelo vigoroso esforço de elaboração reflexiva desses fatos a partir de um patamar de pertinência que se propõe a considerá-los no mesmo plano teórico pretendido por Heidegger como adequado à tarefa de seu pensamento.

Não pretendo aqui empreender uma análise exaustiva do livro de Vietta, mas apresentar as linhas gerais de sua posição, sobretudo a partir dos capitulos centrais do livro. Desse ponto de vista, pode-se dizer que o resultado a que Vietta chega representa o contránio simétrico da tese de Habermas e Fanas. ${ }^{2}$ Para Vietta, o que se deixa demonstrar por meio de uma análise escrupulosa dos textos é que existe uma imbricação fundamental entre 0 aprofundamento da reflexão sobre a histónia da ciência e da técnica moderna e o distanciamento crítico de Heidegger, mais que isso, sua decidida rejeição do nacional-socialismo. Este traria à luz, no plano político e sob a forma aberrante do gigantesco, os traços essenciais que caracterizam a vontade coletiva de poder tornada efetividade histórica na figura da moderna ciência experimental. Para Vietta, portanto, Heidegger compreende a mobilização total, a sincronização de todas as forças e recursos produtivos num plano nazista global de economia bélica (Gleichschaltung) como uma forma de

1 VIETTA, S. Heideggers kritik am Nationalsozialismus und an der Technik. Tübingen: Niemeyer, 1989.

2 Cf. FARIAS, V: Heidegger e o nazismo, trad. Sieni M. Campos (Rio de Janeiro: Paz e Terra, 1988); a tradução alemã, publicada em 1989, é acrescida de um importantíssimo prefácio de J. Habermas. Ecos relevantes da polêmica suscitada com a publicação do livro de Farias se encontram em ALTWEGG, J. (ed.): Die Heidegger Kontroverse (Frankfurt a. M. 1988) e NESKE, G. e KETTERING, E: Antwort: M. Heidegger im Gespräch, Pfullingen, 1989. 
manifestação do mesmo impulso vigorante na racionalidade científica moderna, por meio do qual se processa a integração sistemática da totalidade do ente (Welt) no quadro objetivante de um representar operatónio, que prepara e fundamenta a apropriação da natureza (e da natureza humana) pela racionalidade tecnológica.

Nesse sentido, apreender verdadeiramente a essência do nazismo pressupõe a compreensão do fundamento metafísico de que ele é manifestação política, do mesmo modo como configurações históricas de outro tipo também se desvelam, em sua essência, unicamente a partir da mesma raiz metafísica que lhes dá origem. Para Heidegger, esse fundamento metafísico só pode ser evocado na experiência fundamental do ser do ente em sua totalidade e na correlata decisão sobre a essência da verdade, tal como se verificam historicamente no mundo moderno.

Uma tal experiência e sua correspondente decisão sobre a essência da verdade se articulam como ordenação, organização sistemática da totalidade do ente no quadro quantitativo-classificatório da mathesis universalis, tal como paradigmaticamente realizado por Descartes no gesto seminal de instauração filosófica da ratio moderna. Por força dessa operação, a realidade do ente em seu conjunto (Welt) se transforma em conteúdo representativo, em imagem do mundo (Weltbild), integralmente submetido à ação objetivante do um puro sujeito de conhecimento, por intermédio de cuja operatividade, essa totalidade é tornada disponível e explorável pela intervenção do experimento técnico.

Isso constitui o Ansatz (princípio) e o fundamento da interpretação de Sílvio Vietta. Para ele, o pensamento de Heidegger não se move no elemento próprio da sociologia, nem da politica stricto sensu, mas no da filosofia, no âmbito reflexivo da pergunta pelo ser do ente em sua totalidade; seu pensamento se mobiliza a partir de uma meditação sobre a história do destinamento do ser e, por conseguinte, de uma critica da metafisica como horizonte de compreensão da figura moderna do saber, da essência da ciência moderna e de sua realização tecnológica. Técnica e política, como todas as demais esferas da sociedade e da cultura que dão forma ao mundo moderno só podem ser apreendidas em sua verdade a partir de sua fundamentação metafísica, pois é somente na metafisica que se faz, no Ocidente, a meditação fundante sobre a essência do ente que modela uma imagem epocal do mundo, ainda que a história da metafísica se revele como história da experiência do esquecimento do ser na identificação deste com o ente em sua totalidade. Dai a importância do texto a respeito do Zeit des Weltbildes.

"Na metafísica se perfaz a meditação sobre a essência do ente e a resolução acerca da essência da verdade. A metafísica funda uma era ao dar-lhe o fundamento (Grund) de sua forma essencial por meio de uma determinada concepção da verdade. Esse fundamento impera intrinsecamente em todas as manifestações (Erscheinungen) que distinguem essa era. Inversamente, para uma suficiente meditação, o fundamento metafísico tem que se deixar reconhecer nessas manifestações. Meditação é a disposição (Mut) para fazer da verdade dos próprios pressupostos e do espaço das próprias metas aquilo que é o mais digno de questão."3

3 HEIDEGGER, M. Die Zeit des Weltbildes. In: Holzwege, Frankfurt/M. V. Klostermann, 6. ed. 1980 (p. 69 da edição original, p. 73 da 6. ed.). 
Esse texto de 1938 - por conseguinte contemporâneo do vertiginoso crescimento e implementação do regime nazista - se inicia com a indicação daquilo que constitui a dimensão essencial do procedimento reflexivo heideggeriano: trata-se de retornar, ou remontar reflexivamente a partir daquilo que, numa determinada época, é sintoma e manifestação - no caso em questão, de importantes formaçōes históricas do mundo contemporâneo - para tentar apreender quais seriam os primeiros e essenciais pressupostos dessas formações, ou, inversamente, de deriválas desses pressupostos para, somente ao perfazer-se tal derivação, alcançar sua compreensão essencial. Trata-se, por conseguinte, de uma forma de diagnóstico histórico, característico de um procedimento tradicional em filosofia, que consiste em remontar daquilo que é dado à consciência ao que constitui seu fundamento originário, da superfície à profundidade fundante e originária.

Nesse caso, uma das mais expressivas comparações poderia ser efetuada com o procedimento genealógico nietzscheano, para o qual a autêntica compreensão do significado epocal das mais importantes concreçōes culturais da modernidade a filosofia, a arte, a ciência, mas também os mais significativos fenômenos sóciopolíticos - só se faria possivel a partir de sua Ableitung como formas de manifestação da vontade de poder transfigurada nos valores ético-metafísicos do platonismo-Cristianismo, ou seja, de sua integração na lógica do nililismo

Para Vietta, trata-se da 'tentativa de remontar ao 'fundamento' metafísico interior de sua própria era, para poder entender melhor as manifestações dessa era, a partir de seus derradeiros pressupostos internos."4

Vietta dedica especial atenção a esse texto de 1938, cuja versão final publicada ele compara minuciosamente com os originais manuscritos da conferência que lhe deu origem, pronunciada por Heidegger em Freiburg em 9 de junho 1938 e intitulada: "Die Begründung des neuzeitlichen Weltbildes durch die Metaphysik", cujo texto se acha conservado no arquivo Heidegger existente em Marbach. Nos manuscritos preparatórios tanto da versão final da conferência quanto do trabalho definitivamente publicado em 1950, Heidegger faz indicações, com vistas a ulterior aprofundamento da reflexão, a passagens de suas preleções sobre Descartes (1935/6 e a trabalhos de 1937/8), assim como à série de preleções sobre Schelling proferidas em 1936.

A partir dos elementos ali desenvolvidos, poder-se-ia compreender como já naqueles textos se fazem presentes, antes de 1938, indicações sobre o fundamento metafísico que serve de solo comum para as manifestações culturais mais características da modernidade, a saber: 1) da ciência moderna, 2) da técnica moderna, 3) da subjetivação da estética, 4) da empresa cultural e 5) da desdivinização (Entgötterung) do mundo.

A elaboração reflexiva desse fundamento comum é empreendida exemplarmente por Heidegger a partir da abordagem histórica da moderna ciência experimental, especialmente com base na interpretação do significado metafísico do gesto cartesiano de disponibilização da totalidade do ente, como res extensa, à atividade quantificadora-operatória do Subjectum, segundo o ideal prescritivo da mathesis universalis. A partir desse gesto, é pela ordem e pela medida - portanto

4 VIETTA, S: op. cit., p. 20. 
numa ciência universal da quantidade - que se pode estender o conhecimento à totalidade do real, na medida em que todas as coisas podem ser representadas matematicamente: tanto Deus, o ente supremo, cujo conhecimento pode ser efetuado geometricamente, quanto os corpos singulares que constituem o mundo material, tudo pode ser objeto de um conhecimento de tipo matemático. No gesto cartesiano se descerra, pois, segundo Heidegger, o horizonte metafísico da matemática moderna e do pensamento sistemático: com ele, a forma da evidência matemática explicita e fundamenta a certeza metafísica e, em geral, o que há de universal na evidência:

Essa figura da racionalidade científica se articula a um conceito de vontade também especificamente moderno: o conceito de vontade de poder ou, segundo a interpretação de Heidegger, de vontade de vontade. A dominação calculadora do mundo se desdobra em exploração e desgaste (Vernutzung) da natureza por intermédio da intervenção tecnológico-operatória; no conceito moderno de investigação e experimento, na forma contemporânea de organização do saber técnicocientífico em instituições e empresas científicas, é sempre o mesmo movimento de objetivação, exploração e consumo devastador que se atualiza. Fora já à luz desse processo que Heidegger, em 1933, no Discurso de Reitorado que era, segundo ele, um discurso sobre a essência da ciência - depositara esperanças numa espécie de papel destinamental a ser cumprido pelo regime político nacional socialista quanto à elevação de uma nova humanidade à altura de sua correspondência à essência da técnica moderna. E justamente aí residiria o interesse, para Vietta, em apontar a precocidade dos elementos filosóficos que, já em 1935-6, conduzem Heidegger a uma crítica simultânea da técnica moderna e do nacional-socialismo.

Para Vietta, em 1938, tanto na conferência quanto no texto publicado como Die Zeit des Weltbildes, no contexto da critica da Verweltanschaulichung der Welt (transformação do mundo em cosmovisão), Heidegger já teria alcançado uma compreensão profunda da verdadeira natureza do nazismo, apreendendo-o não como degeneração aberrante e episódica, mas como uma das possibilidades autênticas de realização da essência da moderna racionalidade, que no programa cartesiano de sistematização matemática do saber encontra sua fundamentação metafísica. Inequivocamente em 1938 - mas recuando ainda mais, ao material filosófico oriundo dos ciclos de preleções pronunciadas entre 1936-37 - Heidegger se esforçaria por elaborar o diagnóstico da prodigiosa escalada tecnológica nos tempos modernos. Em especial na mobilização total (totale Mobilmachung) nazista, que absorve todas as forças e recursos produtivos, humanos e materiais, na engrenagem anônima da industrialização para a guerra, manifesta-se sem disfarces o caráter agressivo, totalitário da moderna metafísica da subjetividade:

"O processo fundamental da modernidade é a conquista do mundo como imagem (Bild) [...]. Uma vez que essa postura se assegura, desmembra e expressa como cosmovisões (Weltanschauungen), o modemo relacionamento para com o ente em seu decisivo desdobramento se torna disputa (Auseinandersetzung) entre as cosmovisões e, na verdade, não entre quaisquer, mas unicamente entre aquelas que já incluem, com extrema resolução, posições fundamentais do homem. Para esse combate das cosmovisões e de acordo com o sentido desse combate, o ho- 
mem põe em jogo a mais irrestrita violência de calculação, planificação e criação (Züchtung) de todas as coisas. A ciência como investigação é uma forma imprescindivel desse instalar-se no mundo, um dos trilhos sobre os quais a modernidade se precipita para a realização de sua essência, com uma velocidade desconhecida pelos que nisso tomam parte. Com esse combate de cosmovisões, a modernidade ingressa então no decisivo e presumivelmente mais duradouro capítulo de sua história." 5

Nesse contexto, a pesquisa científica (Wissenschaftsbetrieb), faz parte, como forma imprescindivel, do panorama geral do combate das cosmovisões, ou seja, do conflito das ideologias, para o qual o homem moderno mobiliza sua "irrestrita violência de calculação, asseguramento e planificação". Esse processo fundamental de conquista da totalidade do ente pela racionalidade calculatória representa um dos caminhos para a realização da própria essência metafísica da modernidade enquanto vontade de poder. E por essa razão, o caráter titânico, gigantesco do processo em seu conjunto representa também um modo de realização da categoria hegemônica do Quantitativo, na qual e, por intermédio da qual, o ideal moderno de ciência transforma a quantificação, a ordem e a medida, em grade de inteligibilidade e manipulação de todas as coisas.

“O gigantesco é [...] aquilo por cujo intermédio o 'quantitativo' se torna uma qualidade própria e com isso uma espécie distinta de grandeza. Cada era histórica não é apenas diversamente grande em relação às outras; ela tem também, a cada vez, seu respectivo conceito de grandeza. Porém, tão logo quanto à enormidade da planificação e calculação e instalação e asseguramento se transmuda de quantitativo em uma qualidade própria, torna-se incalculável, precisamente por isso, o gigantesco e aquilo que é, em aparência, a todo tempo inteiramente calculável. Isso permanece como sombra invisível, lançada por toda parte sobre todas as coisas, quando o homem se tornou Subjectum e o mundo imagem do mundo (Weltbild)." 6

É nessa sombria perspectiva do gigantesco que Heidegger interpreta a teratologia nazista da 'mobilização' de todas as forças produtivas no circuito dissipatório da militarização. Como deformidade, o nazismo acentuaria caricatamente os traços autênticos da moderna racionalidade técnico-científica, cuja "violência irrestrita de planificação e calculação" se realiza como dissipação do ente por intermédio da técnica. Do ponto de vista de Vietta, portanto, os textos que estamos examinando, e que remontam cronologicamente a 1936-38 antecipam decisivamente, tanto em lucidez quanto em capacidade analítica de penetração, as posições críticas de Heidegger em relação à técnica, tal como aparecem, por exemplo, em Überwindung der Metaphysik de 1942 ou nos escritos ainda mais tardios do assim chamado 'segundo Heidegger': Para tentar acentuar e como que tornar plástica tal antecipação, permito-me citar textos de 1942, que podem inequivocamente ser compreendidos como ilustração dos conceitos elaborados em Die Zeit des Weltbildes: "O desgaste do ente é, enquanto tal e em seu percurso, determinado por meio do armamentismo (Rüstung) em sentido metafísico, por

\footnotetext{
HEIDEGGER, M. Op. cit., p. 87, 6. ed., p. 92.

Id., p. 88, 6. ed., p. 93.
} 
intermédio do qual o homem se faz 'senhor' do 'elementar' [...] As 'guerras mundiais' e sua 'totalidade' já são conseqüêencias do abandono do ser. Elas compelem ao asseguramento de uma forma permanente de desgaste. Nesse processo, também o homem está incluído, ele que não oculta por mais tempo o caráter de ser a mais importante matéria prima."?

Como se pode perceber no texto citado, a referência à "guerra total" (Goebbels, Ludendorf) e ao "senhorio sobre o elementar" inserem imediatamente a reflexão sobre a técnica no mesmo registro da reflexão crítica sobre a monstruosidade do nacional-socialismo. Nesse sentido, tanto a técnica quanto o nazismo se deixariam compreender a partir de sua recondução à mesma instância metafísica fundante da experiência moderna do ser do ente e da forma da verdade.

Por essa razão, Vietta minimiza a importância da polêmica histórico-filológica tão prenhe de conseqüências políticas envolvendo a publicação, em 1953, do texto correspondente à preleção posteriormente denominada Einführung in die Metaphysik. Acompanhemos, mais uma vez, a leitura do célebre trecho: "O que é oferecido hoje como completa filosofia do nacional-socialismo, mas que nada tem a ver com a interna verdade e grandeza desse movimento (a saber com o encontro entre a técnica planetariamente determinada e o homem moderno) [...]."

Como é sabido à exaustão, os críticos acusam Heidegger de insinceridade quanto à presença, já no manuscrito de 1935, do complemento, entre parênteses, no qual figura a polêmica frase a respeito da "verdade e grandeza" do movimento nacional-socialista. Segundo eles, a frase teria sido acrescentada por Heidegger retrospectivamente em 1953, por ocasião da nova publicação do texto, com a intenção velada de retratação retroativa. Por meio de tal expediente, Heidegger justificaria seu erro de avaliação, recorrendo ao argumento segundo o qual, já em 1935 - portanto cerca de dois anos depois do Discurso de Reitorado - ele contrapunha à forma então vigente do nazismo real uma concepção idealizada, destinamental do nacional-socialismo, para a qual a "verdade e grandeza" daquele movimento consistiria em promover a elevação do homem moderno à altura da essência da técnica. A confusão entre essa interpretação essencial e o nazismo real estaria, portanto, na base de seu fatídico erro político em 1933.

Para Vietta, no entanto, a polêmica deixa de ter sentido não apenas por não ser mais, atualmente, decidível por critérios filológicos rigorosos. Ela não teria importância por razões sobretudo filosóficas. Se considerarmos o contexto da preleção Einführung in die Metaphysik de 1935 e a ele acrescermos as preleções já anteriormente mencionadas (1936-7), que serviram de preparação para as reflexões que deram origem ao texto de 1938 Die Zeit des Weltbildes, chegaremos fatalmente à conclusão que a categoria de "Grandeza" não pode encerrar qualquer

7 HEIDEGGER, M. Vorträge und Aufsätze. 5. ed. Pfullingen: G. Neske, 1985, p. 87 s.

8 Cf. ainda: "Uma vez que o homem é a mais importante matéria prima, pode-se contar com que, com base nas pesquisas químicas atuais, serão instaladas algum dia fábricas para a produção artificial de material humano. As pesquisas do químico Kuhn, distinguido esse ano com o prêmio Goethe da cidade de Frankfurt, já abrem a possibilidade de dirigir a produção de seres vivos machos e fêmeas planificadamente de acordo com as necessidades respectivas" (id., p. 91).

9 HEIDEGGER, M. Einführung in die Metaphysik, Gesamtausgabe, II. Abt. B. 40, ed. Petra Jaeger, Frankfurt a. M. 1983, p. 208. 
conotação positiva; a partir desses elementos, não se poderia razoavelmente considerar que em 1935 - muito menos, por conseguinte, em 1953 - a frase de Heidegger pretendesse celebrar a grandeza de qualquer 'verdadeira' ideologia nacional-socialista, o contrário seria verdadeiramente o caso: " $O$ 'colossal', o conceito próprio de 'grandeza' do fascismo estaria em que ele exibe, de modo extremamente marcante, algo especificamente moderno: o próprio domínio do pensar calculador, o domínio da categoria de quantidade - e, com efeito, intensificado no 'colossal' - a dominação, portanto, do moderno pensar-dominador, para o qual tudo o mais: cosmovisões, ideologias, etc., é apenas funcionalmente submetido. Essa argumentação é preparada nas preleções de 1935-6 e claramente configurada na mencionada conferência" [1938 OGJ.]. ${ }^{10}$

Em apoio de sua interpretação, Vietta recorre à nota $\mathrm{n}^{\circ} 4$ do texto da conferência "Die Begründung des neuzeitlichen Weltbildes durch die Metaphysik" (1938), que contém uma extraordinariamente importante discussão crítica com o Discurso de Reitorado, nota suprimida por Heidegger, mais tarde, por ocasião da versão impressa daquela conferência. Para reconstruí-la na íntegra, Vietta reproduz literalmente o texto da nota, de acordo com o manuscrito de próprio punho de Heidegger.

"A meditação sobre a ciência aqui consumada não está 'em contradição' com o que o que diz e exige 'a auto-afirmação da universidade alemã' (1933). Pois aquele discurso é um científico saltar-por-sobre a 'modernidade' e da 'ciência demasiado hodierna' ( $p$. 7) para deixar emergir a essência da ciência a partir de um saber mais originário. Esse saber, porém, só há que ser fundado na discussão (Auseinandersetzung) com o primeiro começo do pensar ocidental e no tomar a sério a pergunta de Nietzsche, que foi colocada ao fim e como fim desse pensar ( $p$. 12). Aquele discurso não entra na essência da ciência moderna, e isso significa não entra em Descartes. Mas a posição fundamental 'metafísica' a partir da qual, naquele discurso, se perfaz a meditação (p. 6) é a mesma a partir da qual se perfaz a presente meditação sobre a 'ciência moderna'. Lá é pensada uma ciência futura, que se torna novamente um saber, aqui é concebida uma ciência manifestamente ainda por longo tempo 'atual', que dissolveu o saber da ciência e, no lugar dessa perda, teve que deixar surgir as 'cosmovisões' e delas recebe a força impulsora de seu empreendimento. Mas vale também para a ciência moderna aquela frase pronunciada naquele Discurso: "Toda ciência é filosofia, pode ela querer sabê-lo ou não'. Ao renegar a filosofia, a ciência moderna é filosofia."11

Do ponto de vista da penetrante interpretação de Vietta, essa passagem representa uma notável autocrítica de Heidegger. Em 1938 Heidegger teria discernido o erro capital de seu Discurso de Reitorado, de 1933: este teria consistido em ter saltado por sobre $o$ inteiro processo da modernidade para, a partir dos primórdios do pensar antigo, poder obter um outro novo-começo também no presente. Ele teria, então, operado uma espécie de curto circuito entre a esperança de renovação do saber, a partir do retomo à fonte originária da metafísica, a evocação pensante de uma outra forma do espirito que já se anunciara nos primórdios, com

10 Vietta, op. cit., p. 31.

11 Apud Vietta, op. cit. p. 32. 
o Führer e com o movimento nacional-socialista. O erro teria incluído, pois, uma falsa compreensão da essência do Führer e uma subestimação da força da histónia do ser no mundo moderno.

"Somente por meio da crítica radical do pensar moderno - de sua pretensão sistemática, de sua forma de 'racionalidade', de seu procedimento de dominação, da 'vontade de poder' nele suprassumida - é que se manifesta para Heidegger, em geral, quais fatores efetivamente cunham seu tempo - também e justamente o tempo do fascismo. E só quando compreendeu isso é que teve que se tornar claro para ele que o Discurso de Reitorado tinha produzido um 'curto circuito' no mais verdadeiro sentido da palavra. A auto-reflexão de Heidegger sobre seu Discurso de Reitorado não se distancia da esperança numa 'futura' forma do saber que não seja reificante, sistematizadora. Mas ela se distancia da - curto-circuitada e falsa identificação de uma outra forma do espírito com o nacional-socialismo. Pois ele, o estado nacional-socialista, Heidegger o compreende então crescentemente como uma conformação gigantesca desse mesmo pensar moderno."12

A partir dos elementos trabalhados até esse momento, podemos fixar, com Vietta, os resultados de sua exposição de conjunto dos traços fundamentais da crítica heideggeriana da técnica e do nacional-socialismo:

1 - No mais tardar a partir de 1935-36, Heidegger opera com um retículo de interpretação que permite a ele inserir criticamente tanto o fascismo quanto a técnica moderna, ambos considerados como figurações culturais sintomáticas, no contexto de sua história da metafísica ocidental por ele compreendida como história do crescente subjetivismo da vontade de poder, da escalada planetária da dominação tecnológica. Considerado do ponto de vista da história acontecência do ser, esse processo histórico se apresenta como uma forma radical de 'esquecimento do ser' 'desertificação' 'desolação (Ödnis), desgaste do mundo, de Niilismo, no sentido do terminus nietzscheano.

2 - O processo histórico que, na figura do fascismo, vem à luz de forma marcadamente brutal e clara não é conceitualmente transparente, em seus pressupostos histónico-filosóficos, àqueles mesmos que o levam a efeito. Por conseqüência, os 'líderes' aparecem agora, para Heidegger, como sendo uma espécie de cegos agentes de execução do acontecer histórico que dirigem e levam avante, mas não são capazes de discernir em seus devastadores pressupostos e implicações.

3 - Cosmovisões, ideologias, 'valores', 'idéias' são secundários perante o fundamento metafísico de que são formas de manifestação. São mobilizados unicamente para desempenhar uma função de estabilização, de justificação e fundamento da dominação. Em estilo nietzscheano, 'valores' e 'idéias' - ideologias são apenas formas de expressão do niilismo.

4 - Aquilo que é compreendido por Heidegger como o teor seminal do fascismo pertence a um largo processo temporal da modernidade, que não se encerrou com o fim do fascismo e se prolonga, manifestamente ou oculto, na moderna exploração técnico-econômica do mundo e, com isso, ainda permanece ativo, para além das fronteiras do final da guerra. "Heidegger admite até que a fase de des-

12 Vietta, op. cit., p. 33. 
gaste técnico-econômico será um processo particularmente duradouro de decadência histórica da metafísica ocidental. Pode-se acrescentar que ele admite que essa fase desfar-se-ia, repeliria a filosofia como forma do saber, porque ela não precisaria mais da filosofia como forma do saber. E ela não precisa mais da filosofia porque esta já está supressa naquela". ${ }^{13}$

5 - Cumpre acrescentar, como resultado geral, que a imputação, por Habermas e outros, de uma inalterada cumplicidade de Heidegger em relação ao nazismo não é sustentável em face dos textos.

Poder-se-ia também avançar o juízo de acordo com o qual a reflexão crítica sobre a história da ciência moderna, elaborada a partir da compreensão de seu horizonte metafísico não apenas impõe um afastamento em relação às equivocadas esperanças depositadas no movimento nacional-socialista, como também torna possivel a verdadeira inteligência radical de sua essência. Porisso mesmo, ela estaria em melhores condições para apreender, nos avatares contemporâneos da ciência e da política a permanência daquele mesmo teor seminal da desenfreada vontade coletiva de poder que sobrevive na 'mobilização total' da natureza para fins de apropriação tecnológica.

A título de conclusão, gostaria de aduzir algumas observações críticas em relação às teses de Vietta, observações cujo propósito consiste em nos servir de elementos para discussão.

a) Tomemos como ponto de partida a interpretação que Vietta oferece para a passagem relativa à Wahrheit und Grösse do movimento nacional-socialista. Para que possamos admitir que tais termos não implicam qualquer sentido positivo, torna-se necessánio admitir, sem problematizar, duas ordens de convicção: a) é necessário admitir que Heidegger, já em 1935, teria consumado em seus traços definitivos a compreensão filosófica do nacional-socialismo como concreção particular e desfigurada da essência da metafísica da subjetividade - isto é, como autêntica figura histórica da vontade de poder. Isso, contudo, tornaria dispensável a lenta elaboração reflexiva levada a efeito por meio da Auseinandersetzung com Descartes (1936-38), com Schelling (1936), e com o próprio Nietzsche (1936-42); o mesmo se poderia dizer em relação ao marco cronológico de crítica da metafísica eleito pelo próprio Vietta (1938).

Tal conseqüência se apresentaria como inevitável, pois, a se admitir o argumento de Vietta, se a frase em questão estivesse originalmente inserida no manuscrito de 1935 - e somente assim o argumento faz sentido - então já naquela época a verdade e a grandeza do nacional-socialismo consistiria em sua integração no caminho da modernidade para a realização de sua essência, ou seja, para a precipitação da totalidade do ente na gigantesca maquinação operatória, o que tornaria desnecessário o percurso teórico acima aludido, percurso cuja maturação viria à luz com "Die Zeit des Weltbildes".

b) Essa interpretação não parece encontrar apoio explícito em textos de Heidegger. Parece, pelo contrário, contrariar o próprio depoimento-testamento a Der Spiegel, onde Heidegger parece abonar a interpretação corrente que distingue

13 Id., p. 46. 
uma conotação positiva nos termos 'verdade e grandeza', no sentido de um conceito próprio, talvez utópico de nacional-socialismo, alternativo ao nazismo real.

$\mathrm{O}$ texto cuidadosamente reproduzido por Vietta, do qual fizemos a citação integral algumas páginas atrás, não parece confirmar, de modo inteiramente convincente, a interpretação segundo a qual Heidegger teria admitido, num exercício de autocrítica, ter cometido um erro, senão teórico, ao menos procedimental em seu Discurso de Reitorado. Para poder sustentar tal posição, Vietta tem que fundir, sem distinção, duas ordens de argumentação:

a) Heidegger teria se equivocado ao vincular (identificar) ao programa nacional-socialista seu próprio programa de retorno à fonte originária da metafísica para recuperar, também no presente, um novo começo para o saber lo que significaria reconquistar uma nova forma do espírito, diferente da dominação objetivante da moderna racionalidade técnico-científica].

b) A esse equívoco se sobreporia um outro, mais fundamental: Heidegger teria se enganado ao pretender poder recuperar esse saber originário saltando por sobre a Auseinandersetzung com a moderna forma da racionalidade, em especial com Descartes, como se fosse possivel obter acesso a esse segundo começo sem realizar a tarefa prévia de desconstrução da tradição metafísica. Como reflexão sobre a essência da ciência, o Discurso de Reitorado teria consistido, portanto, num erro metafísico entrevisto a partir de 1935-36 e definitivamente corrigido em 1938 com a Fundamentação da imagem moderna do mundo pela metafísica, uma vez que a meditação inicial não teria sido realizada pelo único caminho legítimo possivel, a saber, pela via da rememoração da história do ser e da desconstrução da metafísica da subjetividade.

Ora, a identificação desse pretenso equívoco teórico parece desautorizada pelo próprio Heidegger. Este parece insistir - precisamente no texto citado por Vietta - tanto na diferença quanto na complementaridade entre as duas vias de abordagem do novo começo, sobretudo ao afirmar que suas posições de 1938 não estão em contradição (Widerspruch) com o Discurso de Reitorado. Pelo contrário, o texto citado por Vietta é explícito ao afirmar que "a posição fundamental 'metafisica' a partir da qual, naquele discurso, se perfaz a meditação é a mesma a partir da qual se perfaz a meditação sobre a 'ciência moderna"'.

3) Isso parece servir de indicativo para o próprio procedimento de Vietta, com o que adentramos na terceira ordem de observações críticas. Esse exagero de interpretação - que sobrecarrega desnecessariamente a importância de determinadas passagens - talvez se explique pela pretensão recôndita de revelar que Heidegger não apenas não deixou de se tornar consciente e de refletir em profundidade a respeito do sentido epocal daqueles fenômenos a respeito dos quais seus adversários continuam a acusá-lo de ofuscamento, como também - suplantandoos em penetração e sagacidade filosófica - foi capaz de discernir os pressupostos metafísicos desses fenômenos, cujas conseqüências perduram e se aprofundam mesmo depois de sepultado o tempo do nazi-fascismo e da versão nazista da 'totale Mobilmachung'. Tais-conseqüências não se colocam, de modo algum, na esfera de disponibilidade e controle da vontade humana, individual ou coletiva. 
Eles se investem de tal magnitude metafísica que sua realização histórica possivel ameaça a própria essência do homem.

A tal diagnóstico, Vietta só pode chegar por meio de uma adesão tácita ao programa pós-metafísico do próprio Heidegger. Vietta parece tomá-lo como procedimento suficiente para dar conta integralmente da reflexão sobre a técnica no mundo moderno, sem se preocupar em questionar se a reflexão heideggeriana, por mais indispensável que seja para nos auxiliar a colocar e equacionar algumas das questões e dilemas fundamentais de nosso tempo, pode ser simplesmente assumida sem recuo crítico. Porisso mesmo, ao final do livro, tem-se sempre a impressão que o esforço para reconduzir a polêmica a respeito da posição ético-política de Heidegger a seu verdadeiro patamar teórico não consegue se furtar a uma semiarticulada apologia do filósofo. 